\section{Guitar Increases Male Facebook Attractiveness: Preliminary Support for the Sexual Selection Theory of Music}

\author{
Sigal Tifferet*, Ofir Gaziel, Yoav Baram \\ Ruppin Academic Center, Emek Hefer, Israel \\ *Author for correspondence (tifferet@ruppin.ac.il)
}

Music is a universal phenomenon that has genetic and brain-localized features. As such, it warrants adaptive evolutionary explanations. While some scholars believe that music arose as a by-product of other adaptations, others argue that music is likely to have served some adaptive function, for example in coalition signaling or mother-child bonding. The sexual selection theory of music suggests that music serves as a signal in mate selection. While this claim is prevalent, it lacks empirical evidence. A facebook experiment revealed that women replied more positively to friendship requests from a man shown in a photo holding a guitar. These results offer initial support for the sexual selection theory of music.

\section{Keywords}

music, sexual selection, facebook, attractiveness

\section{Introduction}

From the dawn of mankind, music has accompanied humans. The earliest instrument that was found is an ancient flute dating back 40,000 years ago (Adler, 2009). Not only did music arise early in mankind's prehistory, it arises early in the development of infants. Musical predispositions can be found in the first months of an infant's life (Trehub, 2001), suggesting their innate nature. In fact, some features in musicality have distinct brain localizations (reviewed by Peretz, 2006) and even a genetic basis (Stewart \& Walsh, 2002). Music is also a cultural universal (Nettl, 2005), highly prevalent in different cultures and within cultures. Behavioral phenomena like music that (1) appeared early in prehistory, (2) are apparent in infants, (3) present brain localization, (4) have a genetic basis and (5) show cross-cultural patterns, warrant evolutionary explanations (Miller, 2000; Schmitt \& Pilcher, 2004).

There is a debate regarding the evolutionary adaptive function of music. Pinker (1997) argues that music does not have an adaptive function, and it is only a byproduct of the natural selection of language capacities. Some suggest that music serves as a coalition signaling system (Hagen \& Bryant, 2003; Merker, 2000), while others suggest that it is linked to mother-child bonding (Falk, 2004; Trehub, 2003). Another well-known theory is Miller's (2000) sexual selection theory of music, attesting that human musicality was selected through sexual selection.

The idea that music may serve as a sexual signal in mate choice dates back to Darwin (1871) who suggested that:

All these facts with respect to music and impassioned speech become intelligible to a certain extent, if we may assume that musical tones and rhythm were used by our half-human ancestors, during the season of courtship, when animals of all kinds are excited not only by love, but by the strong passions of jealousy, rivalry, and triumph. (Darwin, 1871, p. 880)

Miller (2000) argues that music is a biological adaptation used by males to signal quality. Musical ability may make an individual attractive by signaling that the individual has (1) a genetic advantage, such as fine motor skills or a high capacity to learn, or (2) the necessary resources needed to master an instrument (Miller, 2000). Musical ability may also signal higher prenatal testosterone, as suggested in a study comparing male musicians with the general population (Sluming \& Manning, 2000). While Miller's (2000) claim that music is used in sexual selection is prevalent and widely reviewed, it has very little empirical evidence in humans (Fitch, 2006).

In order to test Miller's (2000) sexual selection theory of music, we conducted an online experiment using facebook as a mating setting. We hypothesized that a facebook profile photo of a man holding a guitar would receive more positive responses from young single women in comparison to a facebook profile of the same man without a guitar.

\section{Method}

Participants

100 females listed as members of student facebook groups in Israel (Tel-Aviv University and Ben Gurion University) who were identified in their facebook status as single. The mean age as reported on the facebook profiles was $24.4(\mathrm{SD}=1.7)$.

\section{Procedure}

In an experiment, two identical facebook profiles 

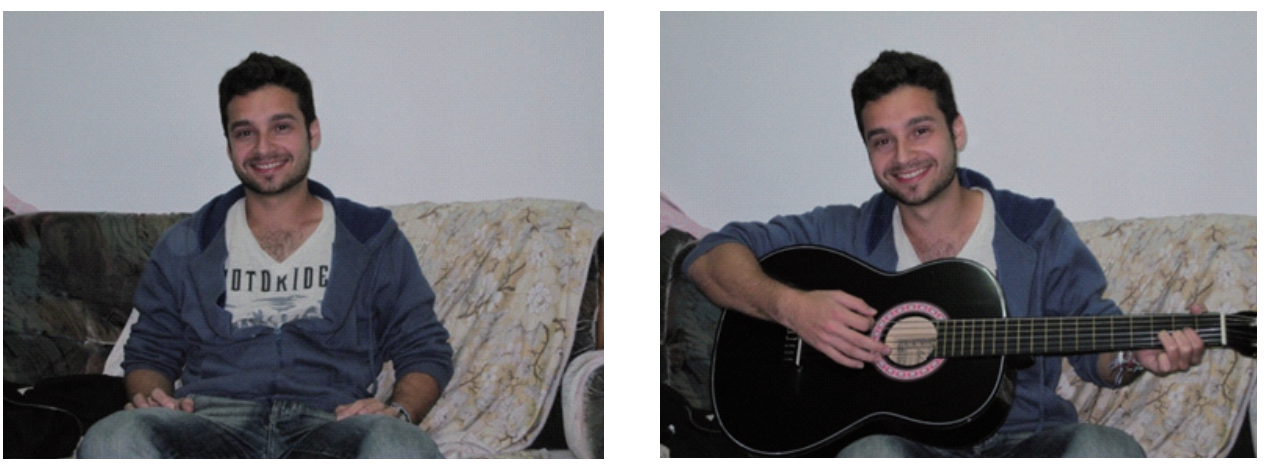

Figure 1. Facebook profile photos for experimental and control group

were created. One was accompanied by a photo of a smiling young man holding a guitar; the second showed the same man without the guitar (see Figure 1). A friendship request was sent from each profile to 50 different women with the accompanying text: "Hey, what's up? I like your photo." Responses were categorized into positive ("I like yours too") or negative ("I have a boyfriend" or no response). Twenty friendship requests were sent every day for five consecutive days (so that the facebook account will not be shut off). If a response was not received after a week, it was considered as a negative response. At the end of the study participants who responded positively received a letter of explanation.

\section{Results}

While only five of the fifty women (10\%) responded positively to the friendship request that was sent by the profile without a guitar, 14 of the 50 women (28\%) responded positively to the friendship request that was sent by the profile with a guitar $(p=.03$, Fisher's exact test).

\section{Discussion}

The objective of this research was to check whether women find men holding a guitar more attractive than men without one. Although the sexual selection theory of music is well-known, there is very little empirical evidence for it in humans. Using a sample of Israeli female students who identified themselves as single in their facebook profile, we found that positive responses were more prevalent to friendship requests of a man holding a guitar. This finding is especially compelling since it was conducted outside of a laboratory in a real-life (albeit online) situation; therefore the participants were not aware at first of participating in a study. These results support the hypothesis that men who play a musical instrument are perceived as more attractive, and provide initial support for the sexual selection theory of music. It should be noted that proposing that music has a role in sexual selection does not mean that it does not have additional functions. Once selected for one function, musical displays may have come to play multiple adaptive roles.

Several questions are raised by this analysis. First, we tested only women's reactions to apparent musical ability in men. While some signals are considered attractive by both males and females (e.g., facial symmetry; Rhodes, 2006), others show sex differentiation (e.g., status; Buss, 1989). It would be interesting to see whether musical displays are similarly attractive in both males and females, or whether they are especially valued in men. In most avian species, only males sing (Brenowitz, Margoliash, \& Nordeen, 1997). However, in some species, females do attract males through singing as well (Garamszegi, Pavlova, Eens, \& Moller, 2007). With some exceptions (Fitch, 2006), singing is more prevalent in males in other species, but not so in humans (Hauser \& McDermott, 2003). In most human cultures, musicality is not limited to males and may have served a function in mother-child bonding (Cross, 2007).

Second, it would be interesting to test whether the attractiveness of male musicians is limited to short-term relations, or extends to long-term relations as well. If musical ability mainly signals that a man has good genes, we would predict a greater effect in the case of short-term relations $(\mathrm{Li}$ $\&$ Kenrick, 2006). The effect may also be restricted to certain men. The specific man in this study seems to have masculine features (see Figure 1) which may be 'softened' by the guitar. Perhaps the guitar effect would not be as pronounced with a more feminine looking man.

In light of the sexual selection theory of music, we hypothesized that a man holding a guitar would signal his quality by advertising his genetic capabilities or his resources (Miller, 2000). Exhibiting the possibility to enjoy leisure time has long been recognized as a symbol of higher status (e.g., Veblen, 1899), therefore holding a guitar can imply that a man has the necessary resources to allocate time to music. However, holding a guitar may have increased attractiveness due to other reasons. The presence of the guitar may have made the man in the photo more attractive not because 
it represented musical ability, but simply because it offered more data on an anonymous person. Future studies, therefore, should investigate the effect of photos showing other items including other instruments. Finally, the study results are also limited at present to Israeli female students. The results should be replicated, especially in natural fertility cultures. It is also worth noting that results obtained in a facebook study may not necessarily reflect off-line interactions.

In sum, we showed that in the facebook realm, men who hold a guitar in their profile photo are perceived as more attractive. These novel results provide initial support for the sexual selection theory of music and will hopefully stimulate additional tests.

\section{References}

Adler, D. S. (2009). Archaeology: The earliest musical tradition. Nature, 460, 695-696. doi:10.1038/460695a

Brenowitz, E. A., Margoliash, D., \& Nordeen, K. W. (1997). An introduction to birdsong and the avian song system. Journal of Neurobiology, 33, 495-500. (doi: 10.1002 (SICI) 1097-4695(19971105)33:5<495::AIDNEU1>3.0.CO;2-井

Buss, D. M. (1989). Sex differences in human mate preferences: Evolutionary hypotheses tested in 37 cultures. Behavioral and Brain Sciences, 12, 1-49. doi:10.1017/S0140525X00023992

Cross, I. (2007). Music and cognitive evolution. In R. I. Dunbar \& L. Barrett (Eds.), Handbook of Evolutionary Psychology (pp. 649-667). Oxford: Oxford University Press.

Darwin, C. (1871). The Descent of Man, and Selection in Relation to Sex. London: John Murray.

Falk, D. (2004). Prelinguistic evolution in early hominins: Whence motherese? Behavioral and Brain Sciences, 27, 491-503. doi:10.1017 S0140525X04000111

Fitch, W. T. (2006). The biology and evolution of music: A comparative perspective. Cognition, 100,173-215. (doi:10.1016 i.cognition.2005.11.009)

Garamszegi, L. Z., Pavlova, D. Z., Eens, M., \& Moller, A. P. (2007). The evolution of song in female birds in Europe. Behavioral Ecology, 18, 86-96. doi:10.1093/beheco/arl047)

Hagen, E. H., \& Bryant, G. A. (2003). Music and dance as a coalition signaling system. Human Nature, 14, 21-51. doi:10.1007/s12110-0031015-Z

Hauser, M. D., \& McDermott, J. (2003). The evolution of the music faculty: A comparative perspective. Nature Neuroscience, 6, 663-668. doi:10.1038/nn1080

Li, N. P., \& Kenrick, D. T. (2006). Sex similarities and differences in preferences for short-term mates: What, whether, and why. Journal of Personality and Social Psychology, 90, 468-489. doi:10.1037/0022-3514.90.3.468
Merker, B. (2000). Synchronous chorusing and human origins. In N. L. Wallin, B. Merker, \& S. Brown (Eds.), The Origins of Music (pp. 315327). Cambridge, MA: The MIT Press.

Miller, G. F. (2000). Evolution of human music through sexual selection. In N. L. Wallin, B. Merker, \& S. Brown (Eds.), The Origins of Music (pp. 329-360). Cambridge, MA: The MIT Press.

Nettl, B. (2005). The Study of Ethnomusicology: Thirty-one Issues and Concepts. Champaign, IL: University of Illinois Press.

Peretz, I. (2006). The nature of music from a biological perspective. Cognition, 100, 1-32. doi:10.1016/i.cognition.2005.11.004

Pinker, S. (1997). How the Mind Works. New York: Norton.

Rhodes, G. (2006). The evolutionary psychology of facial beauty. Annual Review of Psychology, 57, 199-226. (doi:10.1146/annurev. psych.57.102904.190208)

Schmitt, D. P., \& Pilcher, J. J. (2004). Evaluating evidence of psychological adaptation: How do we know one when we see one? Psychological Science, 15, 643-649. doi:10.1111/i.09567976.2004.00734.X

Sluming, V. A., \& Manning, J. T. (2000). Second to fourth digit ratio in elite musicians: Evidence for musical ability as an honest signal of male fitness. Evolution and Human Behavior, 21, 1-9. doi:10.1016/S1090-5138(99)00026-4

Stewart, L., \& Walsh, V. (2002). Congenital amusia: All the songs sound the same. Current Biology, 12, R420-R421. doi:10.1016/S09609822(02)00913-2

Trehub, S. E. (2001). Musical predispositions in infancy. Annals of the New York Academy of Sciences, 930, 1-16. doi:10.1111/j.1749$6632.2001 . t b 05721 . x$

Trehub, S. E. (2003). The developmental origins of musicality. Nature Neuroscience, 6, 669-673. doi:10.1038/nn1084

Veblen, T. (1899). The Theory of the Leisure Class. New York: Macmillan. 